\title{
A Synthesis of the Evidence for Managing Stress at Work: A Review of the Reviews Reporting on Anxiety, Depression, and Absenteeism
}

\author{
Kamaldeep S. Bhui, Sokratis Dinos, Stephen A. Stansfeld, and Peter D. White \\ Centre for Psychiatry, Barts and the London School of Medicine and Dentistry, Queen Mary University of London, \\ London E14NS, UK \\ Correspondence should be addressed to Kamaldeep S. Bhui, k.s.bhui@qmul.ac.uk
}

Received 19 May 2011; Revised 3 August 2011; Accepted 5 August 2011

Academic Editor: David Vlahov

Copyright ( $) 2012$ Kamaldeep S. Bhui et al. This is an open access article distributed under the Creative Commons Attribution License, which permits unrestricted use, distribution, and reproduction in any medium, provided the original work is properly cited.

Background. Psychosocial stressors in the workplace are a cause of anxiety and depressive illnesses, suicide and family disruption. Methods. The present review synthesizes the evidence from existing systematic reviews published between 1990 and July 2011 . We assessed the effectiveness of individual, organisational and mixed interventions on two outcomes: mental health and absenteeism. Results. In total, 23 systematic reviews included 499 primary studies; there were 11 meta-analyses and 12 narrative reviews. Metaanalytic studies found a greater effect size of individual interventions on individual outcomes. Organisational interventions showed mixed evidence of benefit. Organisational programmes for physical activity showed a reduction in absenteeism. The findings from the meta-analytic reviews were consistent with the findings from the narrative reviews. Specifically, cognitive-behavioural programmes produced larger effects at the individual level compared with other interventions. Some interventions appeared to lead to deterioration in mental health and absenteeism outcomes.Gaps in the literature include studies of organisational outcomes like absenteeism, the influence of specific occupations and size of organisations, and studies of the comparative effectiveness of primary, secondary and tertiary prevention. Conclusions. Individual interventions (like CBT) improve individuals' mental health. Physical activity as an organisational intervention reduces absenteeism. Research needs to target gaps in the evidence.

\section{Introduction}

Although work provide a range of benefits such as increased income, social contact, and sense of purpose, it can also have negative effects on mental health, particularly in the form of stress. The National Institute of Occupational Safety and Health in the US (NIOSH) [1] estimate the following:

(i) $40 \%$ of American workers reported their job was very or extremely stressful,

(ii) $25 \%$ view their jobs as the number one stressor in their lives,

(iii) three fourths of American employees believe that workers have more on-the-job stress than a generation ago.
Given the global recession, financial strain, and job losses, greater work stress might have adverse consequences in UK. The most recent data from the NHS information centre in UK suggest an increase in the suicide rate for the first time since 1998. The number of people committing suicide rose by 329 to 5,706 in 2008 . The rate among men increased from 16.8 per 100,000 in 2007 to 17.7 per 100,000 in 2008 . This increase is being interpreted by politicians and the public as a consequence of the global and national recession, increased job insecurity, risk of loss of jobs, and also stress at work, where the demands on the existing workforce have increased (The Independent, 18th November, 2010).

Approximately 11 million people of working age in UK experience mental health problems. 11.4 million working days were lost in UK in 2008/2009 due to work-related stress, depression, or anxiety [2]. There are also indirect costs, 
TABLE 1: Model for categorising stress management interventions (adapted from de Jonge and Dollard) [17].

\begin{tabular}{|c|c|c|c|c|}
\hline Level & Primary prevention & Secondary prevention & Tertiary prevention & Outcome measures \\
\hline Organisational & $\begin{array}{l}\text { Improving work } \\
\text { content, fitness } \\
\text { programmes, and } \\
\text { career development }\end{array}$ & $\begin{array}{l}\text { Improving } \\
\text { communication and } \\
\text { decision making and } \\
\text { conflict management }\end{array}$ & $\begin{array}{l}\text { Vocational } \\
\text { Rehabilitation and } \\
\text { outplacement }\end{array}$ & $\begin{array}{l}\text { Productivity, turn-over, } \\
\text { absenteeism, and financial claims }\end{array}$ \\
\hline $\begin{array}{l}\text { Individual and } \\
\text { Organizational } \\
\text { interface }\end{array}$ & $\begin{array}{l}\text { Time management, } \\
\text { improving } \\
\text { interpersonal skills, } \\
\text { and Work/home } \\
\text { Balance }\end{array}$ & $\begin{array}{l}\text { Peer support groups, } \\
\text { coaching, and career } \\
\text { planning }\end{array}$ & $\begin{array}{l}\text { Posttraumatic stress } \\
\text { assistance } \\
\text { programmes and } \\
\text { group psychotherapy }\end{array}$ & $\begin{array}{l}\text { Job stressors such as demands, } \\
\text { control, support, role ambiguity, } \\
\text { relationships, change, with } \\
\text { burnout }\end{array}$ \\
\hline Individual & $\begin{array}{l}\text { Pre-employment } \\
\text { medical examination } \\
\text { and didactic stress } \\
\text { management }\end{array}$ & $\begin{array}{l}\text { Cognitive behavioural } \\
\text { techniques and } \\
\text { relaxation }\end{array}$ & $\begin{array}{l}\text { Rehabilitation after } \\
\text { sick leave, disability } \\
\text { management, case } \\
\text { management, and } \\
\text { individual } \\
\text { psychotherapy }\end{array}$ & $\begin{array}{l}\text { Mood states, psychosomatic } \\
\text { complaints, subjective } \\
\text { experienced stress, physiological } \\
\text { parameters, sleep disturbances, } \\
\text { and health behaviours }\end{array}$ \\
\hline
\end{tabular}

for example, through "presenteeism" when employees are at work but are too unwell to function fully [3]. Stress at work also can lead to physical illness, psychological distress and illness, and sickness absence [3, 4]. Stress, depression, or anxiety accounts for $46 \%$ of days lost due to illness and are the single largest cause of all absences attributable to work-related illness [5]. Psychosocial work stressors such as job strain, low decision latitude, low social support, high psychological demands, effort-reward imbalance, and high job insecurity have all been implicated as causes of work stress-related anxiety and depressive illnesses [6]. However, psychosocial work stressors can only be tackled by organisational and systemic strategies and policies.

\section{The Conceptualisation of Occupational Stress}

In order to consider the evidence base, there needs to be some agreement on the meaning of work stress. A popular model of stress considers "inputs" such as job characteristics; for example, excess demands, low control, poor social support, adverse life events such as bereavement or divorce, and additional demands outside of work such as carer responsibilities for a dependent relative or spouse [7-10]. Stress has also been recognised by symptoms or "outputs" such as tension, frustration, or emotional distress. An alternative approach is to theorise that stress is a manifestation of the poor fit between a person and their environment [11]. Stress is then seen to arise due to a discrepancy between the inputs and outputs and the mediating appraisal of stress, personal skills to manage it, and environmental demands and rewards. Transactional models, as those proposed by Lazarus [12] and Cox and Ferguson [13], conceptualise stress as something that unfolds over time within a series of transactions between the person and their environment. Stress is, therefore, elicited and maintained by the individual's actions and perceptions as well as the characteristics of their work environment.

The specific conceptualisations of stress adopted influence the way interventions are constructed to tackle specific mechanisms in order to alter stress and its manifestations.
Cahill [14], Cooper et al. [15], and Marine et al. [16] describe categories of stress management interventions that target the individual or the organisation and specify actions at primary, secondary, or tertiary preventive levels (see Table 1) [17]. Individual interventions include stress awareness training or cognitive behavioural therapy for psychological and emotional stress. Organisational interventions are those that affect whole populations or groups of people and include workplace adjustments or conflict management approaches in a specific organisation. Some interventions target both the individual and organisation, for example, policies to secure a better work-life balance and peer-support groups. Primary interventions aim to prevent the causal factors of stress, secondary interventions aim to reduce the severity or duration of symptoms, and tertiary or reactive interventions aim to provide rehabilitation and maximise functioning among those with chronic health conditions [18].

Although preventive interventions are often advocated, what is the evidence of benefit? The evidence of effective interventions to protect individual mental health and reduce organisational absenteeism rates is difficult to summarise in a manner that is of practical relevance. Therefore, the purpose of this paper is to take the highest level of research evidence (systematic reviews providing narrative synthesis or metaanalyses) and synthesise this evidence to identify the key findings and gaps in the literature on the effectiveness of different stress management interventions for preventing anxiety and depression as the main cause of absenteeism. Consequently, this review of systematic reviews focuses on common mental health problems (anxiety, depression) and absenteeism.

Undertaking a review of systematic review is challenging methodologically for two reasons; there is not a conventional accepted process to produce a meta-review or meta-synthesis across different types of systematic reviews, for different outcomes, and different complex interventions which may defy drawing a singular scientific conclusion that requires all sources of heterogeneity be overlooked [19]. Secondly, the ambition of the review and the form the findings take have, 
TABLE 2: Databases searched.

Medline 1950 to November Week 32008

$$
\begin{gathered}
(N=2,470) \\
(N=1,911) \\
(N=2,313) \\
(N=110) \\
(N=12) \\
(N=432) \\
(N=3) \\
(N=335) \\
(N=41) \\
(N=218)
\end{gathered}
$$$$
\text { PsychInfo } 1806 \text { to January Week } 22009
$$$$
\text { Cochrane database of systematic reviews 4th quarter } 2008
$$$$
\text { Cochrane Methodology Register 4th quarter } 2008
$$$$
\text { Allied and Complementary Medicine } 1985 \text { to January } 2009
$$

British Nursing Index 1985 to January 2009

Health management information consortium October 2008

in part, to reflect the subject matter and the types of interventions that are being reviewed. So, for complex interventions for managing stress at work, there will be organizational and individual interventions, and different disciplinary approaches to the task of meta-synthesis of narrative findings. The notion of a meta-synthesis of narrative findings is itself contested by different qualitative research disciplines from which such approaches have evolved [20,21]. The purpose of this paper is then to draw together literature and findings which are consistent across reviews and methodologically variant studies, where this is possible in order to demonstrate the strength of the findings. However, given the complex nature of interventions to tackle stress at work and that stress itself and mental health are so ill-defined in studies, we also wish to highlight findings that emerge from a critical comparison of reviews; we also wish to highlight the findings that are pertinent to well-defined common mental disorders (anxiety and depressive states); we also wish to acknowledge that narrative synthesis (or meta-synthesis, as it is sometimes called) may reveal complexities in the field of study such that the findings cannot be neatly expressed as a single statement of efficacy or effectiveness, but that interventions might need to be developed to target specific subpopulations. The findings can, thus, signal the methodological issues that future research must tackle.

\section{Methods}

The review identified all systematic reviews of evidence on stress management interventions in the workplace and summaries, tabulated extracted, and then synthesized the evidence for the relative merits of different interventions. Consistent with previous work, we restricted the review to papers published since 1990, as recency in the literature is important to ensure the evidence is related to contemporary concepts of stress and work, and to ensure the current work conditions are represented in the evidence synthesis, rather than historical work conditions. The databases searched are listed in Table 2.

The search terms used were:

"psychological ill health or anxiety or stress or distress or burnout," "stress management or intervention or rehabilitation or prevention,"

"work or job or employee or sick leave or occupation or workplace adjustments or employee assistance programmes."

3.1. Inclusion and Exclusion Criteria. The criteria used for inclusion were
(a) english language articles,
(b) reviews published from 1990 to July 2011,
(c) systematic reviews,
(d) reviews with data/narrative synthesis,
(e) meta-analyses.

The articles excluded were

(a) theoretical and educational reviews,

(b) those published prior to 1990 .

3.2. Types of Reviews. The total number of reviews initially retrieved after excluding duplicates was 7845 (see Table 1). Twenty three reviews that met the inclusion criteria included 499 primary studies/publications. Data were extracted using the headings set out in Table 3 by two researchers working independently. A third researcher checked for and resolved any discrepancies with reference to the original publications.

3.3. Outcome Domains. The reviewed studies included many outcomes which ranged from physical health measures (e.g., cardiovascular measures) to psychological and psychiatric measures (e.g., well-being, psychological distress, burnout, general mental health, anxiety, depression, stress, psychiatric symptoms, and psychosomatic symptoms) to organisational measures (e.g., employee satisfaction, motivation, absenteeism). In this paper, we focus only on articles reporting, (a) individual outcomes of symptoms of anxiety and depression (including severe stress if measured by a specific rating scale of anxiety and depression) or anxiety and depressive illness formally assessed using specific diagnostic or psychometric measures and (b) absenteeism as an important organisational outcome as this has an economic cost to the employer. 
We included key words of anxiety and depression and severe stress as inclusion criteria, but many studies and reviews are not flagged on this basis, and the findings pertaining to these outcomes are often hidden in tables of results. Piloting showed that searches specifically for anxiety and depression did not easily permit us to identify all studies that might include anxiety and depression as outcomes; this was only possible after reviewing the full-text paper. Thus, we kept our original searches broad in order to be satisfied all such paper that met our inclusion criteria would be included.

3.4. Analysis. Table 3 presents descriptive information on the twenty three reviews including the dates of published studies/papers included in the reviews, the number of published studies/papers, the prevention level (i.e., primary, secondary, and tertiary), whether the interventions were targeting the individual (I) or the organisation $(\mathrm{O})$ level, and which level the outcomes specified: individual mental health (I) and/or absenteeism (O).

Due to the heterogeneity of the published reviews in terms of the methodology used (i.e., meta-analyses versus narrative synthesis or meta-narratives), the analysis and synthesis of meta-analytic reviews is reported first (see Table 4; 11 reviews), then the narrative synthesis reviews (Table 5; 12 reviews), each annotated to indicate individual and organisational interventions, and individual and organisational outcomes (see Table 3).

Including narrative reviews permitted evaluation of indepth information that might be overlooked in meta-analytic reviews, as this information is important for constructing appropriate interventions and implementing them in order to prevent severe stress and anxiety and depression at work. For example, components of an appropriate organisational intervention will be difficult to capture in a meta-analytic review given these interventions will vary between organisations; only in-depth descriptions can capture the components that can then be considered for similar organisational contexts.

For meta-analyses, the effect sizes and original conclusions are presented, along with the outcomes used, where these were reported (Table 4). For narrative reviews, we present the key narrative conclusions (or evidence summary statement), along with the number of studies finding improvement $(\uparrow)$, deterioration $(\downarrow)$, or no effect $(\leftrightarrow)$. This was done for the same two outcomes: mental health and for absenteeism (Table 5).

Judgements about the number of studies finding a positive, negative or no effect in the narrative synthesis were challenging, as many studies tended to use words such as stress, psychological distress, psychosomatic disorders interchangeably, and negative findings may not have been reported. We only rated studies as having effects on mental health (anxiety and depression), where it was clear they had used a specific measure of mental disorders or severe stress either alone or as part of a composite measure of mental health and wellbeing. Where there was doubt, we did not include the study in the data. This is an advance on existing reviews which tend to group all types of stress, including that associated with anxiety and depression, and other types of measures of stress such that the findings are interpreted with reference to a large number of emotional and health states. We felt this approach would not permit us to isolate the findings of relevance to the preventing common mental disorders which are the most important cause of sickness-related absenteeism.

\section{Results}

Eleven reviews included meta-analyses [16, 22-31]; 12 included a systematic or literature review [32-43] with metanarrative conclusions (see Table 5).

As set out in Table 3, of the twenty three reviews, four reported on individual interventions only (three with a metaanalysis) $[26,27,31,36]$; three of these assessed their impact on individual and organisational outcomes [26, 31, 36], whilst the other one assessed impact on individual outcomes only [27]. There were three reviews that examined the effectiveness of only organisational interventions $[24,32,40]$. Of these, Parkes and Sparkes [40] and Bond et al. [24] reviewed organisational outcomes, whereas Egan et al. [32] reported on individual outcomes.

Six reviews included studies that looked separately at individual and organisational interventions in the same studies [16, 37, 39-42]. Of these, Mimura and Griffiths [39] reported only on individual outcomes, the rest reported on both individual and organisational outcomes. The remaining seven reviews assessed interventions at both individual and organisational levels $[23,25,29,30,33-35]$. Of these, one looked only at organisational outcomes [34], and one looked at individual outcomes [28]. There were no studies that assessed interactions between the two levels of outcome.

4.1. Reviews Reporting Meta-Analysis of Effect Sizes. Eleven reviews [16, 22-31] reported effect sizes from meta-analyses (Table 4) on mental health and absenteeism. The overall impression from the meta-analytic reviews is that the effect size is greater at the individual level for individual interventions compared with organisational interventions, and that organisational or mixed interventions can also impact on the mental health of individuals.

4.2. Individual Outcomes: Mental Health. Of these eleven reviews, six showed that individual interventions lead to benefit on individual mental health outcomes $[16,23,25-27$, $31]$. Five reviews of organisational interventions $[16,23,25$, $28,30]$ together showed mixed evidence of benefit on individual outcomes; thus Richardson and Rothstein [23] and van der Klink et al. [25] showed no benefit, whilst Marine et al. [16], Martin et al. [28] and van Wyk and Pillay-Van Wyk [30] showed some benefit. Richardson and Rothstein [23] and van der Klink et al. [25] also reviewed mixed interventions, both of which showed benefit at the individual level on mental health status.

4.3. Organisational Outcomes: Absenteeism. Four reviews found individual interventions did not impact on absenteeism $[23,25,28,30]$. There was mixed evidence of benefit 


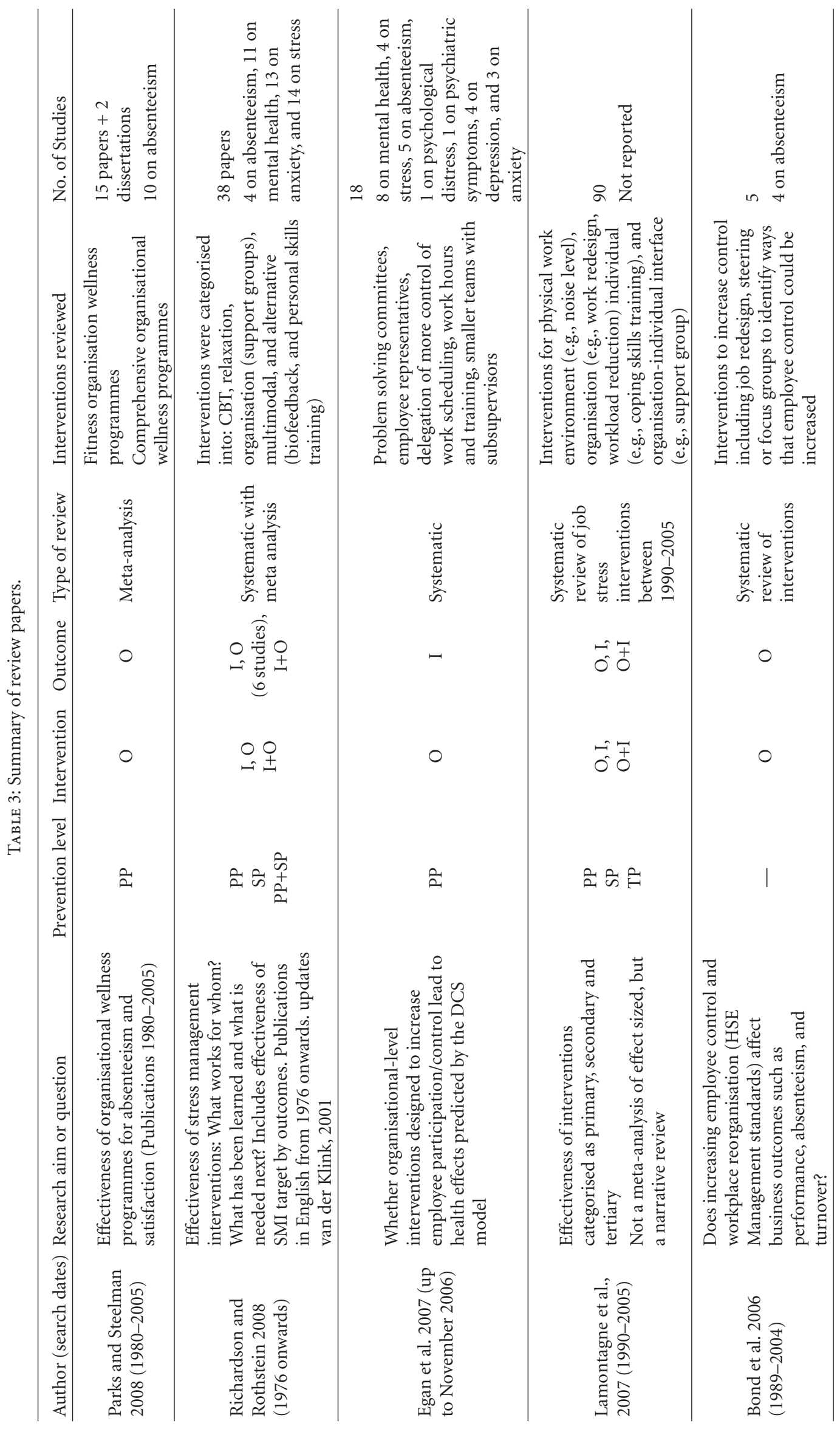




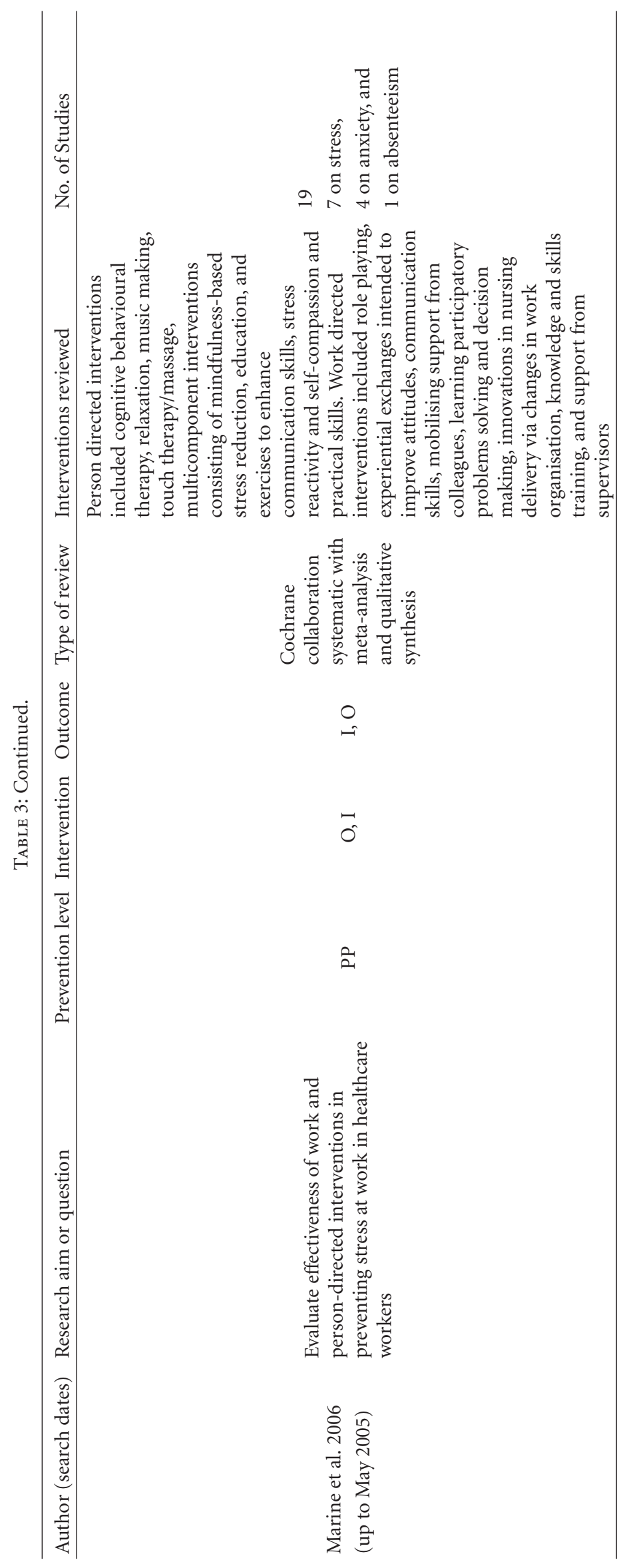




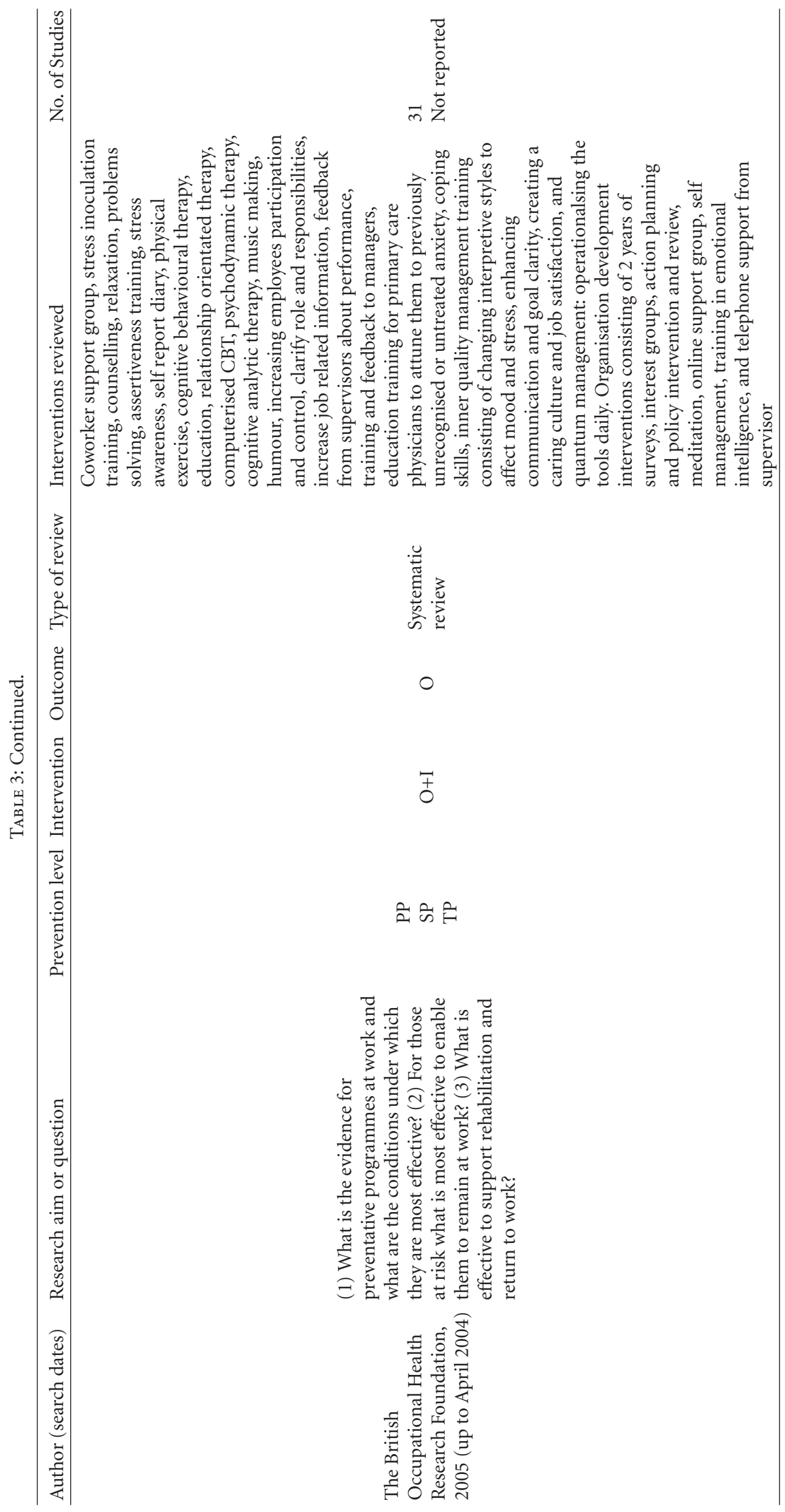




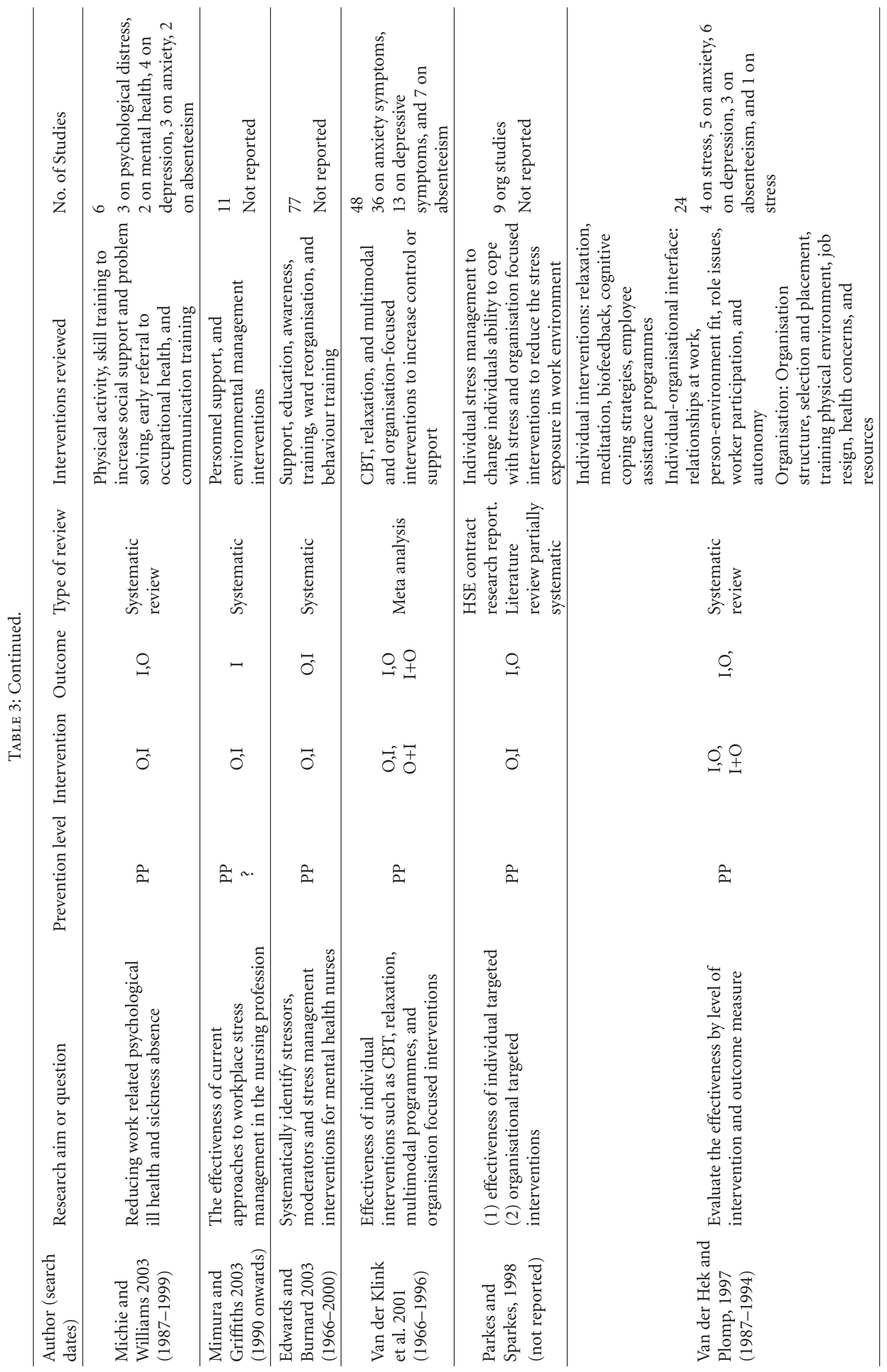




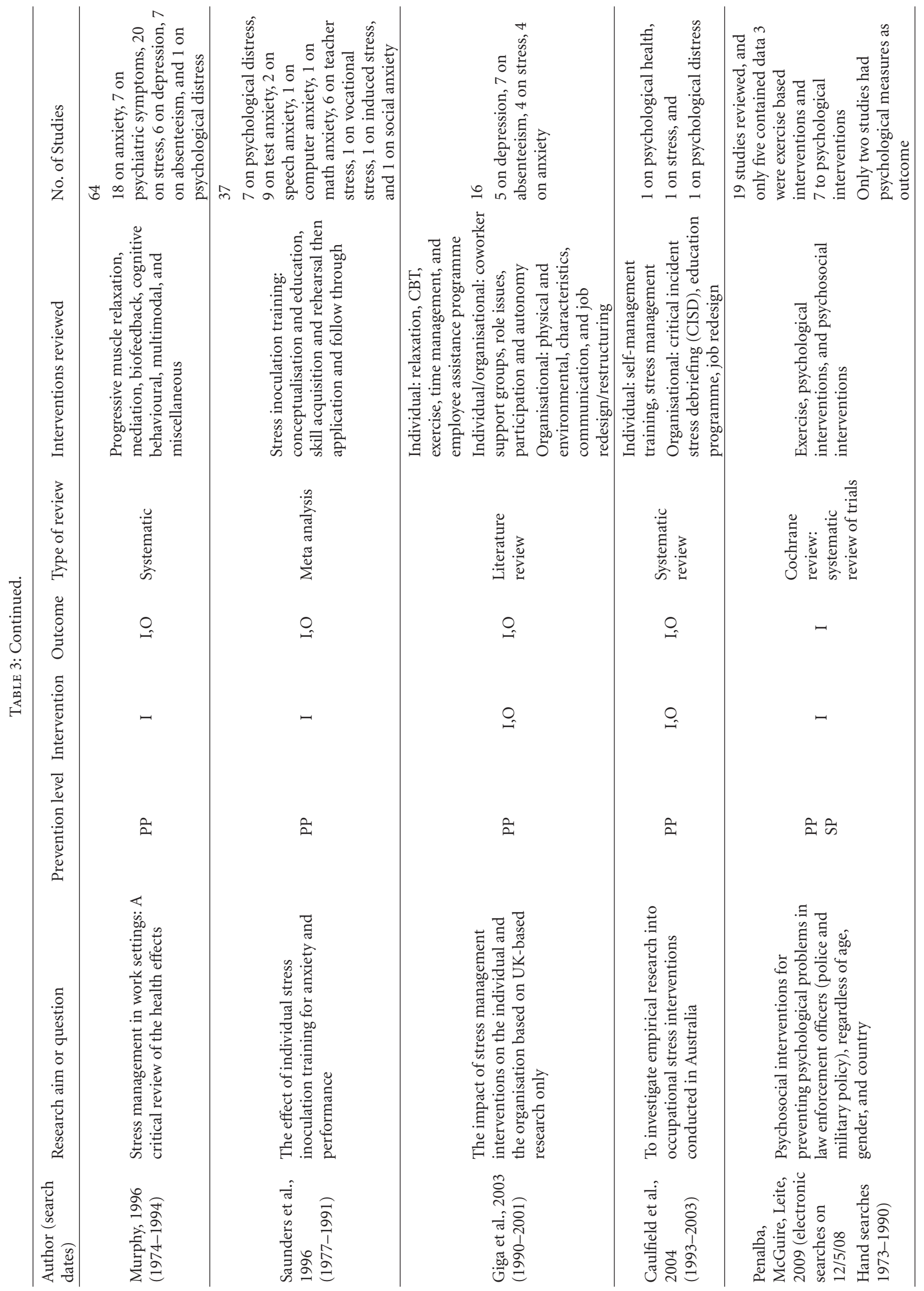




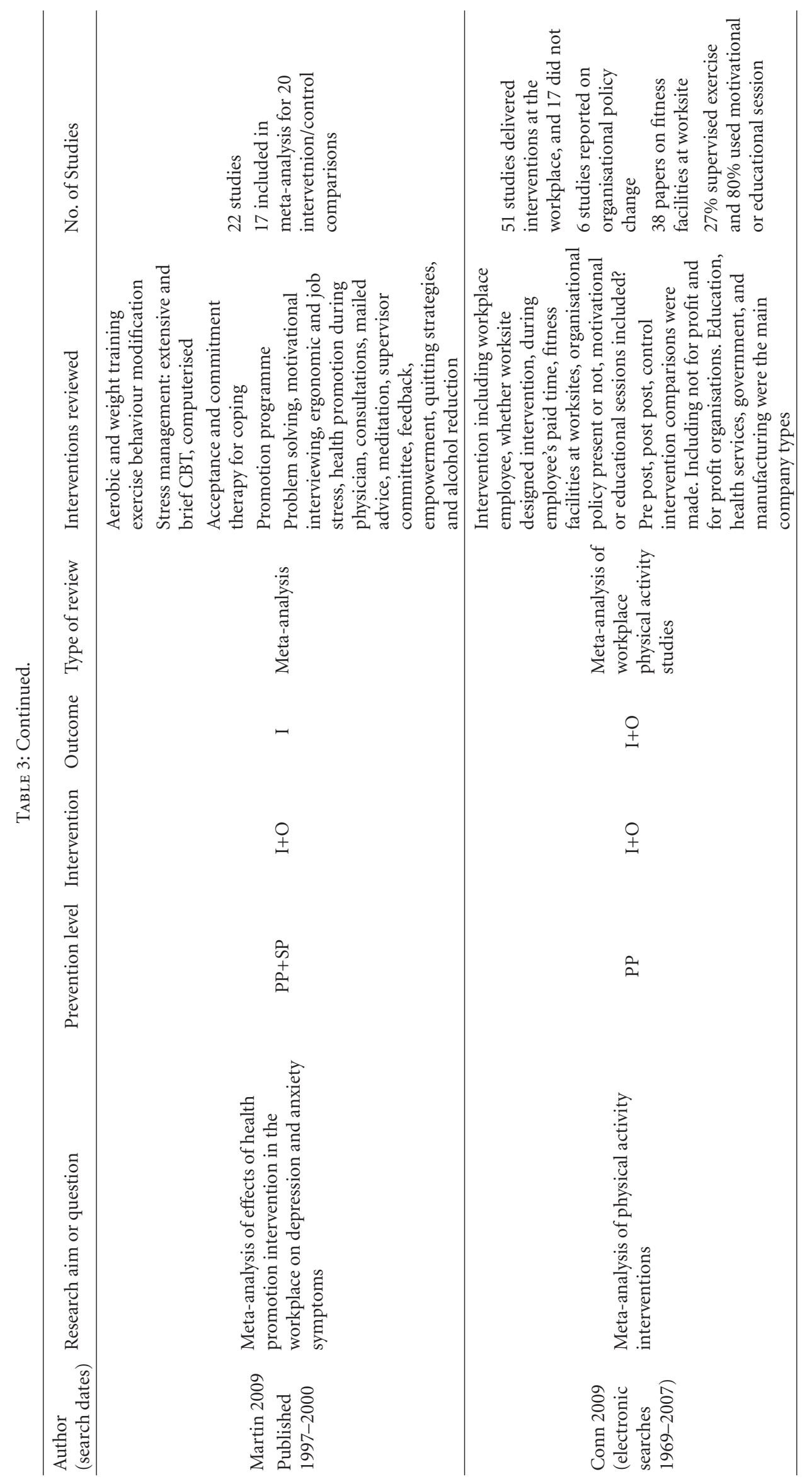




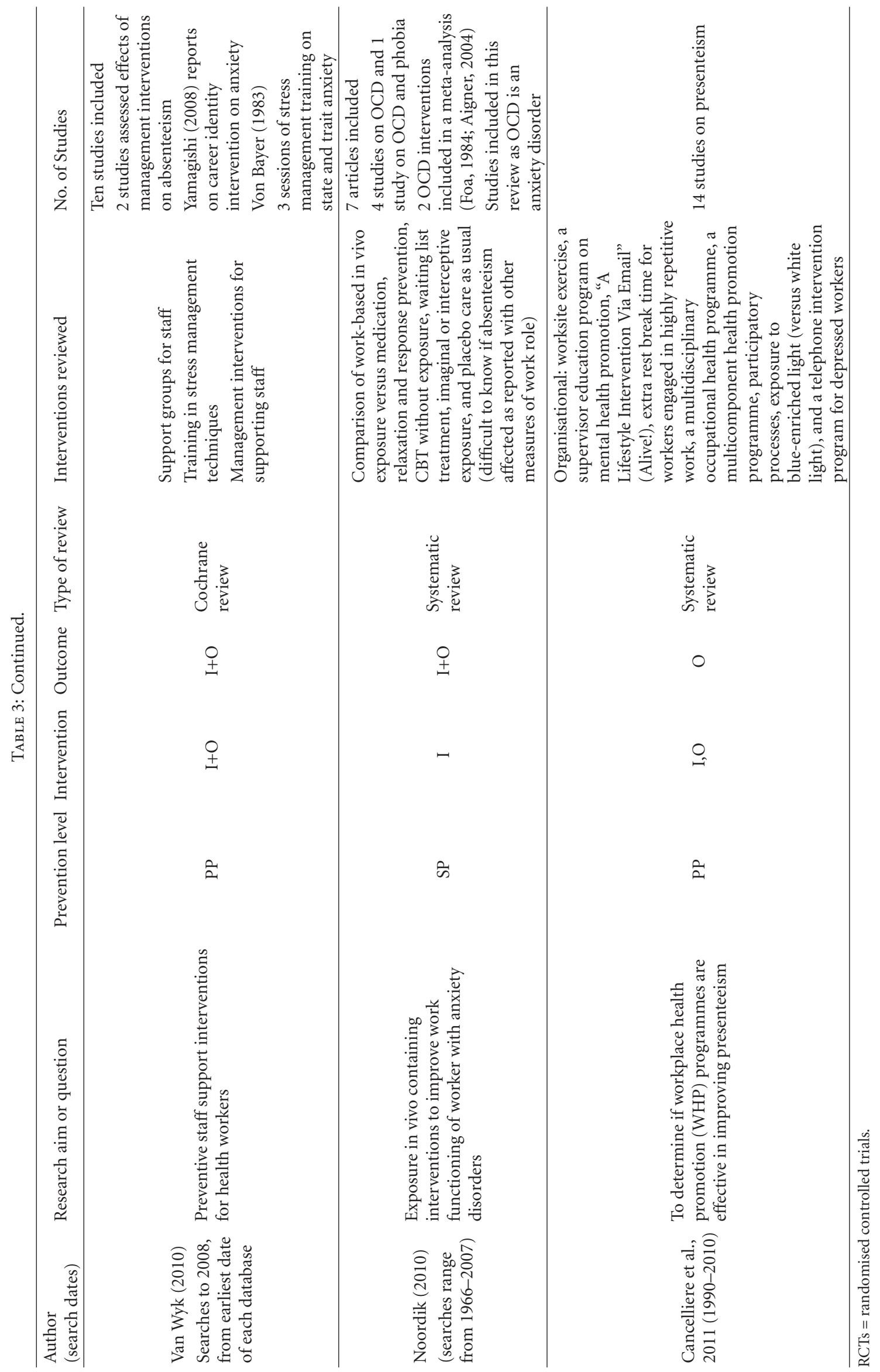




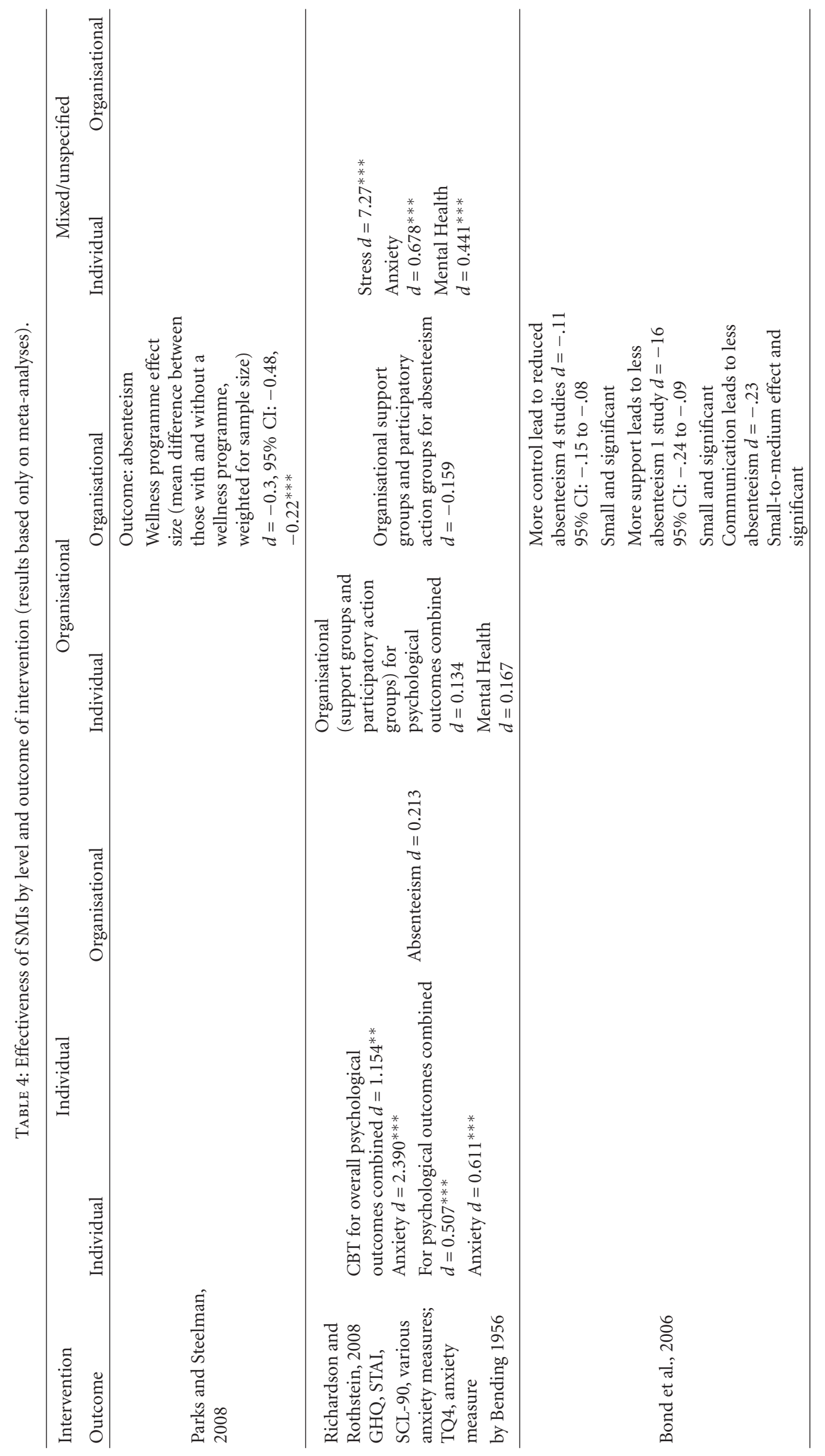




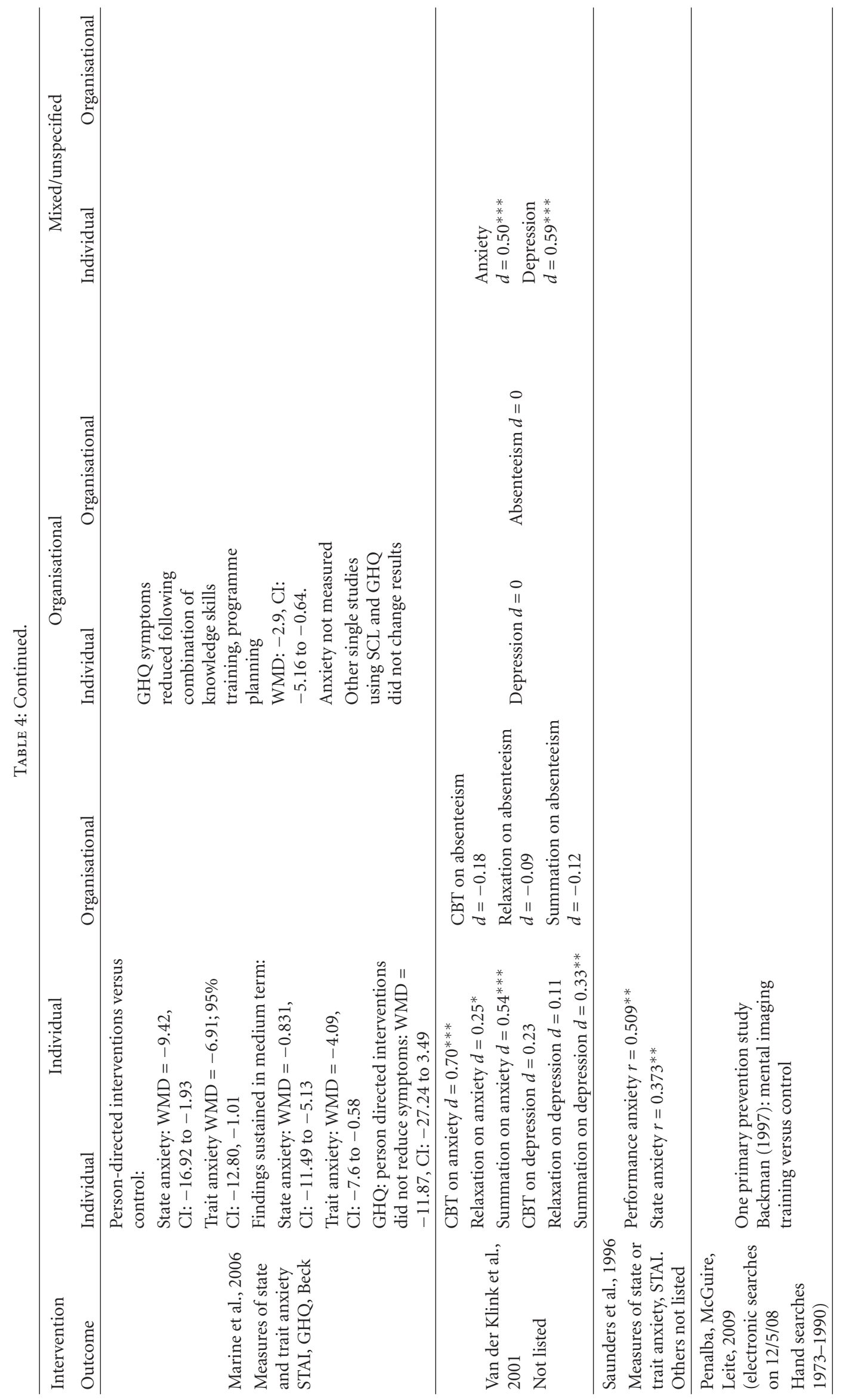




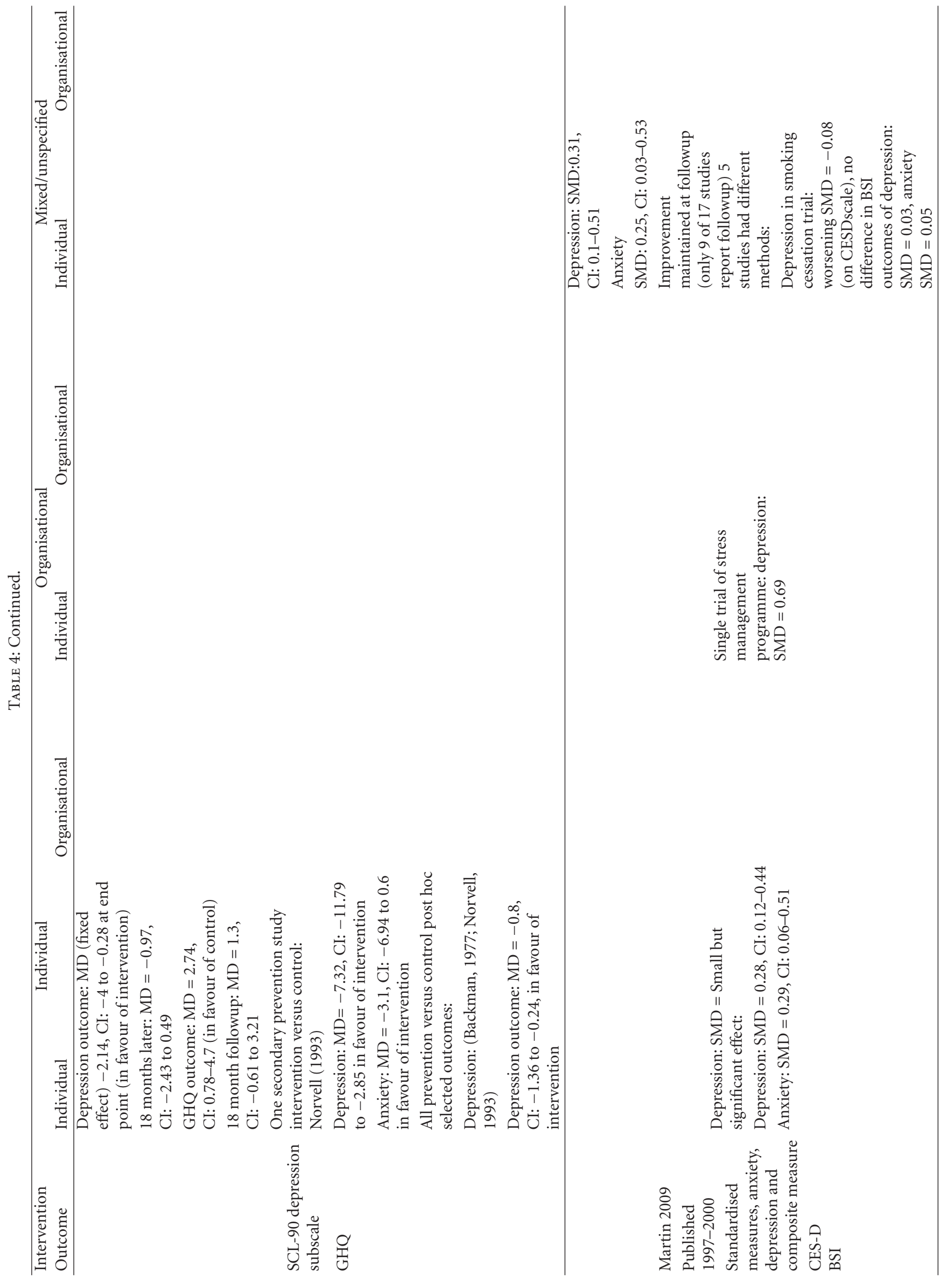




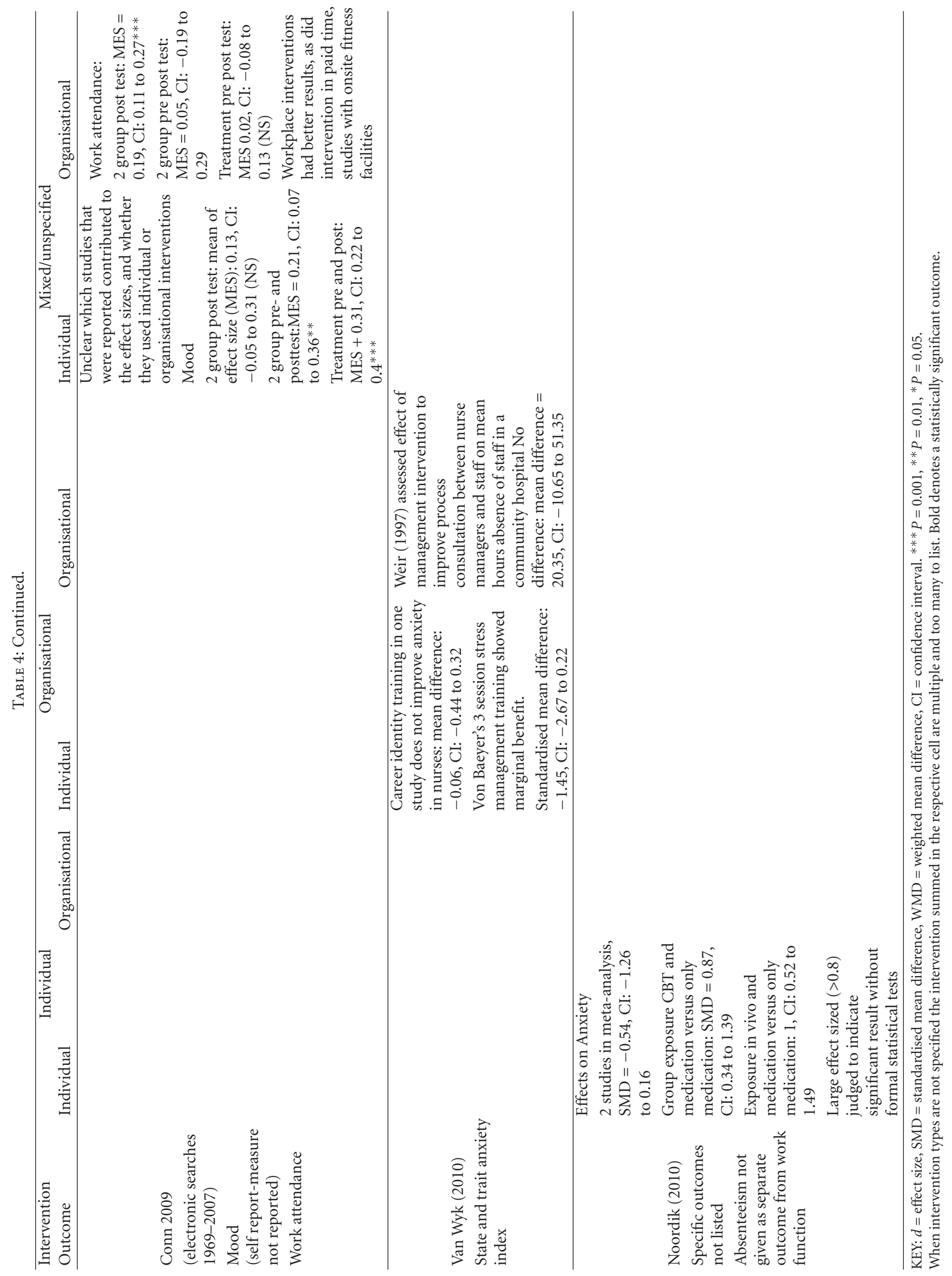




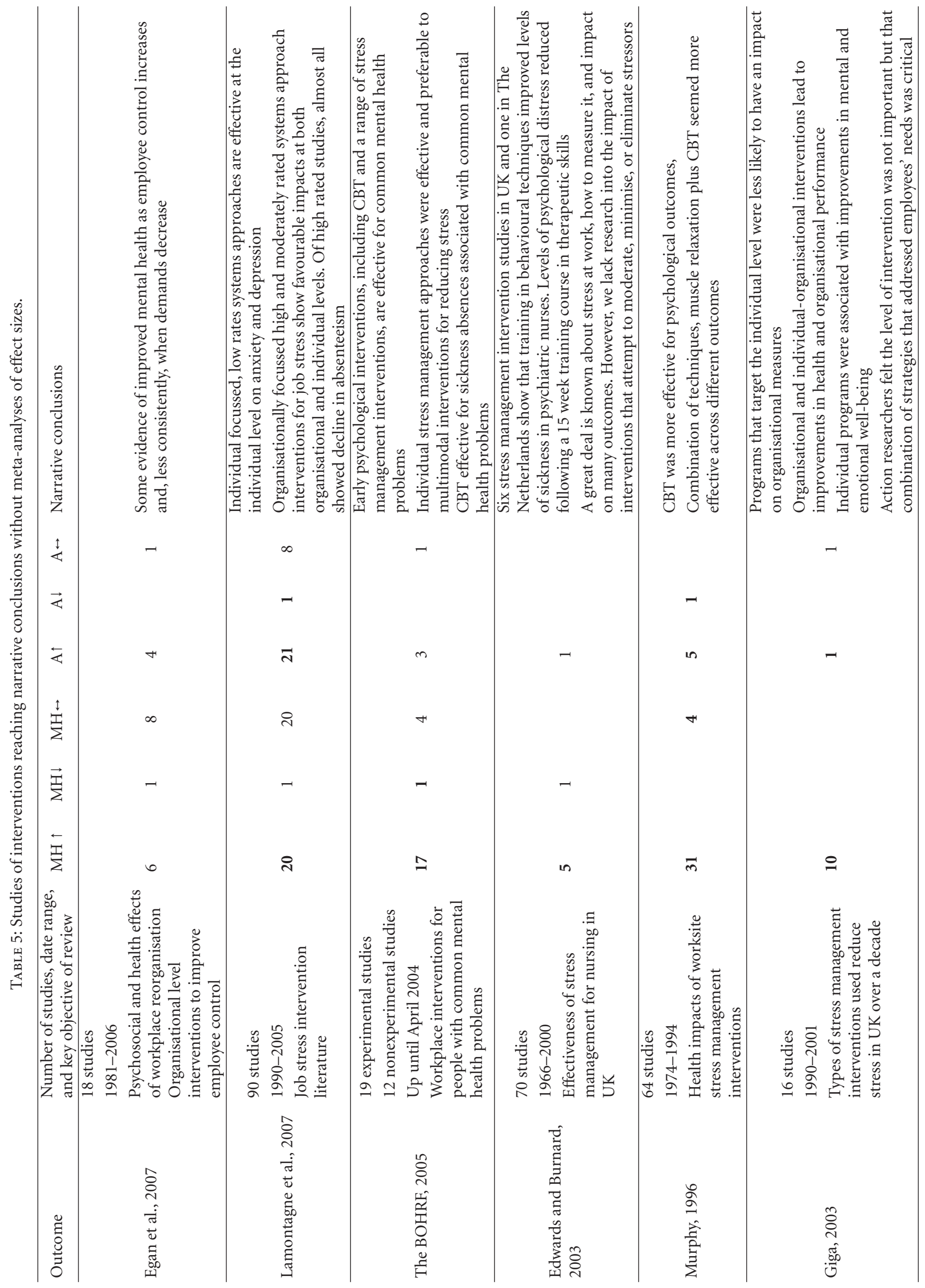




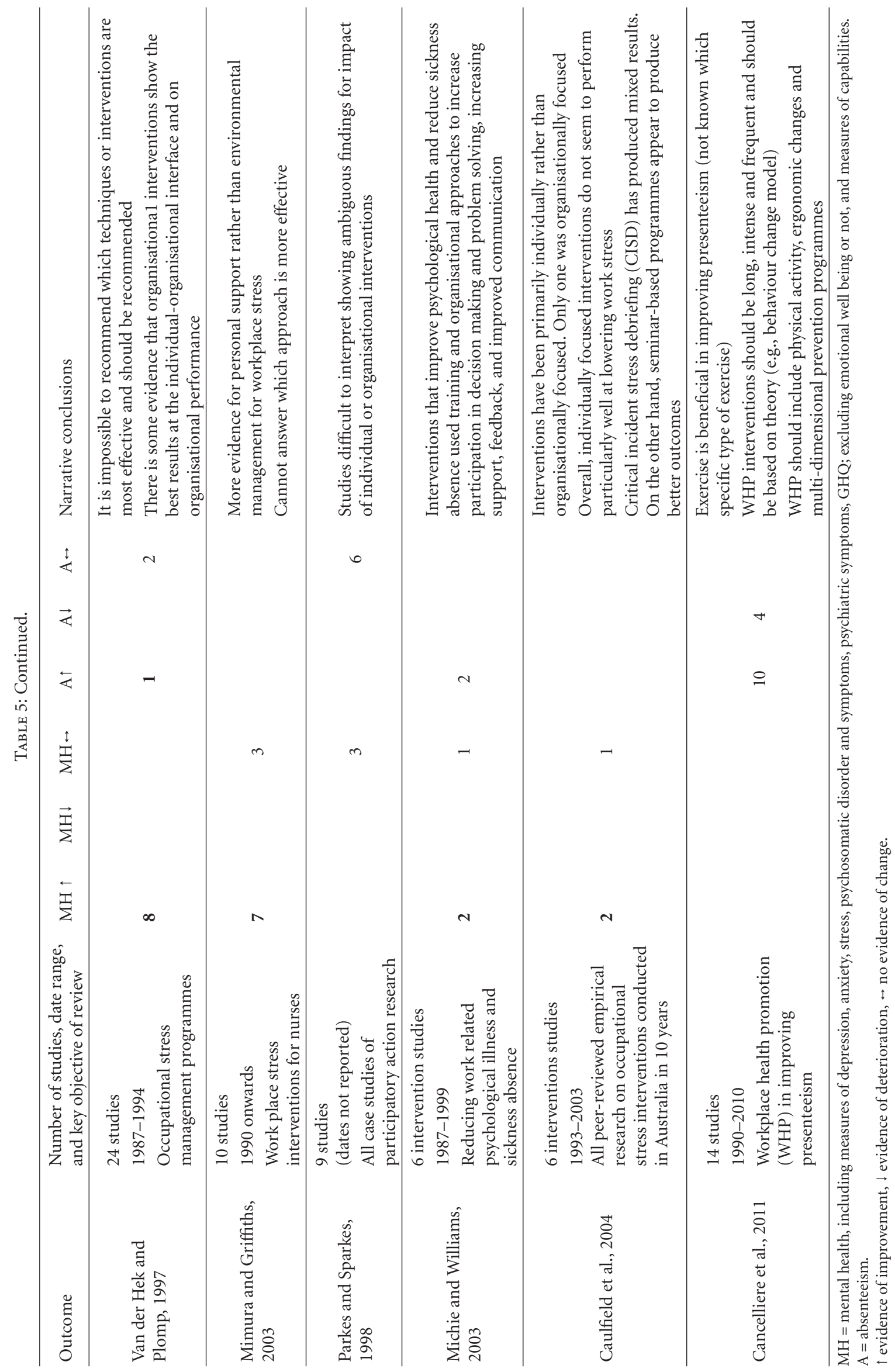


from organisational interventions on absenteeism. Parks and Steelman [22] and Bond et al. [24] found some evidence of benefit, whereas Richardson and Rothstein [23] and van der Klink et al. [25] found no benefit. However, Conn et al. [29] showed clear benefit of organisational physical activity interventions on absenteeism. There were no studies of mixed individual-organisational interventions and impact on absenteeism.

4.4. Reviews Reporting Narrative Conclusions. The overall conclusions from the narrative reviews support the findings from the meta-analyses that individual interventions do provide benefit at an individual level and reduce symptoms of anxiety and depression and stress, but individual interventions do not impact on absenteeism. However, organisational interventions impact at both individual and organisational levels. There are numerous studies of benefit on mental health outcomes, whereas benefit on absenteeism is mainly reported in one review [33] including a number of high quality studies (Table 5). Worryingly, some interventions appeared to lead to deterioration in mental health $[16,32-$ 35] and absenteeism [33, 36] outcomes (see Table 5). For example, Marine et al. [16] identifies smoking cessation to be associated with depression. Although not directly mapping on to absenteeism, preliminary evidence from Cancelliere et al. [43] suggested that some workplace health promotion programmes can reduce presenteeism (being at work whilst unwell). Presenteeism correlated with being overweight, a poor diet, a lack of exercise, high stress levels, poor relationships with coworkers and management.

4.5. The Effectiveness of Specific Interventions. The different types and components of interventions, and whether they are primary, secondary, or tertiary preventive interventions, are set out in Table 3. The majority of studies were of primary prevention. The meta-analytic reviews found that cognitive behavioural programmes consistently produced larger effects at the individual level compared to other types of interventions (e.g., relaxation). Cognitive behavioural programmes were also suggested to be more effective by some of the narrative reviews $[27,31,34-36]$ as well as by some of the metaanalyses $[23,25]$.

Murphy [36] found that multimodal interventions (or combination strategies), which involved CBT produced the most consistent, significant results; a result which was not supported by one meta-analytic review [25]. Overall, the reviews suggested that organisational level interventions are too scarce and there is also a lack of studies that assess organisational-level outcomes. However, two meta-analytic reviews $[22,29]$ found that participation in organisational wellness programmes was associated with decreased absenteeism and increased job satisfaction. These were the only meta-analytic reviews of organisational based interventions and organisational-level outcomes. Finally, there are insufficient studies to comment on the potential complementarity of interventions that operate at primary, secondary, and tertiary prevention levels [33]. Four studies investigated both primary and secondary prevention but not their interaction $[23,27,33$, 34].

\section{Discussion}

As anticipated, the evidence was in complex form. Our methods of isolating findings related to anxiety and depression, and partitioning the tabulation and extraction and synthesis by individual/organisational interventions and outcomes provides a rich, complex but authentic picture of the evidence base. There are indications for which interventions are effective and also gaps in the evidence. Reviews had to take account of many interventions that differed by their components, mode of delivery and whether they targeted individuals or organisations. This made it difficult for all of the reviews to compare benefits from any single intervention across a number of studies, except for CBT or physical activity. There were also many different outcome measures for assessing anxiety and depression, and many proxy measures of mental health, sometimes without clarity about which outcomes were used in the meta-analyses. In part, these were not specified due to the way multiple outcomes were handled in the analysis. The reviews used standardised differences including mean differences and mean effect sizes, and standardised differences and means. Using a consistent set of outcomes to measure anxiety and depression in future primary studies will ensure that future reviews and meta-analyses can overcome these challenges, such that different intervention, of varying complexity and modes of delivery, might be compared more directly for impacts on absenteeism and on anxiety and depression and interactions between the individual and organisational impacts.

Overall, individual interventions show larger effectscompared with organisational interventions or mixed interventions; benefits are seen mainly at the individual level although some studies do show organisational benefits. Given that anxiety and depression are common, and mostly account for sickness absence, it is important to develop an evidence base that is specific to these manifestations of mental distress and illness, with an agreed range of acceptable outcome measures and for interventions that prevent and treat anxiety and depression promptly, as well as encourage early return to work. A small improvement in sickness absence statistics might yield substantial benefits for business viability and provision of services. Standardised methods to measure presenteeism [43] are needed. The only organisational intervention to show convincing effects on absenteeism was physical activity programmes [29], but mental imaging, CBT, and in vivo exposure, each have a useful role, especially in secondary prevention. Although better quality studies should be given greater weight, the quality of individual primary studies was selectively reported, making it difficult to know whether the positive findings reflected better quality studies; certainly, CBT and physical activity interventions are more well defined than say stress management standards or management practices or stress inoculation. Even counselling can take many forms, and there is not a standardised process. Similarly, the duration of 
the interventions and timing of measurement of outcomes was not a characteristic on which reviews drew conclusions; we were unable to draw any metaevidence about timing unless we had looked at primary studies. Strikingly, although many reviews on face value were reviewing the same evidence, the reviews did not all identify the same primary studies, and therefore did not always reach the same conclusions; our meta-review, for the first time, brings together all of the strongest findings. We reviewed 23 reviews, after identifying 7845 potential publications for inclusion. These included 499 primary studies; the majority of reviews made the point that drawing metanarrative or meta-analytic conclusions was difficult because of this diversity in outcomes, intervention, and methods. Had we undertaken a review of 499 primary studies, it is likely we would draw the same conclusions.

Management skills training, and support for staff, along with methods to cope with work stress all seem relevant components, but the review was not convincing about a positive benefit of these and where positive impacts were seen at individual levels $[16,28]$; the effect could not entirely be attributed to improved management standards or working relationships. There has been insufficient research on organisational interventions. These studies are difficult to design and implement and require further research. On the other hand, more and more interest has been generated towards health promotion in the workplace (e.g., exercise) and encouraging individuals to take ownership of health risk behaviours and decisions about health, well-being, and family outside of work. This may be promising, as it requires the workforce to maintain healthy lifestyles generally and within that context to consider work stress rather than consider work as the only venue for health interventions. Organisational measures to increase physical activity show promising results [43].

This review suggests that there is lack of evidence in comparing the relative effectiveness of stress management interventions that operate at both individual and organisational levels, or interventions that encourage an interactive or systemic effect, yet this might yield greater benefits at both levels.

However, there are still a number of evidence gaps. More research is needed in the private sector and in smaller companies as well as research comparing different job types such as education and healthcare to examine whether they respond to the same or different intervention techniques. Similarly, research needs to take into account factors such as socioeconomic status, duration of any effects of interventions, and cost effectiveness. Selection bias may be an important explanation for our findings. For example, organisations with the most stressful work environments are less likely to participate in research as opposed to organisations with little stress amongst employees. Consequently, organisations with low baseline stress levels would make any effects from targeted interventions more difficult to capture. However, preliminary support was found in one meta-analytic review that interventions conducted with employees at high levels of baseline stress appeared to be at least as effective as interventions conducted with employees at low levels of baseline stress [25]. What works for whom and the maintenance of these effects need further research [32].

Finally, there is a relative lack of studies with clinically referred employees. We did find more of these in more recent years (since 2008) and also reviews of health care workers and law enforcement officers who perhaps need specific attention given the unique circumstances and stressors to which they are exposed at work. The few methodologically rigorous studies that have been conducted with patients have not included nontreatment control groups but have compared 2 treatment types. More work might, therefore, be undertaken on populations at risk using secondary and tertiary prevention interventions.

\section{Conclusions}

CBT was the most effective individual targeted intervention for individual outcomes. Encouragement of physical activity at an organisational level seems to reduce absenteeism. Interventions need to be developed that can provide consistent and stronger effects on organisational outcomes such as absenteeism. There were a number of gaps in the literature, particularly studies investigating the influence of specific occupations, and different sized organisations, different sectors of organisations (public, private, and not for profit). Studies of management practices seemed not to show strong effects, but there are still insufficient studies in this area. There were few studies of secondary and tertiary prevention.

\section{Conflict of Interests}

The authors declare that they have no conflict of interests.

\section{Authors' Contribution}

K. S. Bhui conceived of the study, was the principal investigator, provided day-to-day management, and along with SD read the reviews, extracted and tabulated the data and codrafted the paper. S. A. Stansfeld and P. D. White were the coinvestigators to the project, and commented on and edited all drafts of the paper. All authors contributed equally to this work.

\section{Acknowledgment}

This work was supported by the Department of Health in UK to K. S. Bhui.

\section{References}

[1] CDC. Stress at work. Centers for Disease Control and Prevention 2010, http://www.cdc.gov/niosh/docs/99-101/.

[2] "Health and Safety Executive. Stress-related and psychological disorders," Health and Safety Executive 2009 http://www.hse .gov.uk/statistics/causdis/stress/.

[3] J. Jordan, E. Gurr, G. Tinline et al., Beacons of Excellence in Stress Prevention: Research Report 133, Health \& Safety Executive Books, London, UK, 2003.

[4] Health and Safety Statistics 2006/2007, "National Statistics 2010," http://www.hse.gov.uk/statistics/overall/hssh0607.pdf. 
[5] C. Cooper and P. Dewe, "Well-being-absenteeism, presenteeism, costs and challenges," Occupational Medicine, vol. 58, no. 8, pp. 522-524, 2008.

[6] S. Stansfeld and B. Candy, "Psychosocial work environment and mental health - a meta-analytic review," Scandinavian Journal of Work, Environment and Health, vol. 32, no. 6, pp. 443-462, 2006.

[7] J. Siegrist, "Chronic psychosocial stress at work and risk of depression: evidence from prospective studies," European Archives of Psychiatry and Clinical Neuroscience, vol. 258, no. 5, pp. 115-119, 2008.

[8] R. Karasek, "Low social control and physiological deregulation-the stress-disequilibrium theory, towards a new demand-control model," Scandinavian Journal of Work, Environment and Health, Supplement, vol. 34, no. 6, pp. 117-135, 2008.

[9] S. A. Stansfeld, R. Fuhrer, J. Head, J. Ferrie, and M. Shipley, "Work and psychiatric disorder in the Whitehall II study," Journal of Psychosomatic Research, vol. 43, no. 1, pp. 73-81, 1997.

[10] S. A. Stansfeld, H. Bosma, H. Hemingway, and M. G. Marmot, "Psychosocial work characteristics and social support as predictors of SF-36 health functioning: the Whitehall II study," Psychosomatic Medicine, vol. 60, no. 3, pp. 247-255, 1998.

[11] T. Cox, "Organizational culture, stress, and stress management," Work Stress, vol. 5, no. 1, pp. 1-4, 1991.

[12] R. S. Lazarus, "Psychological stress in the workplace," Journal of Social Behavior \& Personality, vol. 6, no. 7, pp. 1991-2013, 1989.

[13] T. Cox and E. Ferguson, "Individual difference, stress and coping," in Personality and Stress: Individual Differences in the Stress Process, C. Cooper and L. Payne, Eds., pp. 7-29, John Wiley \& Sons, Chichester, UK, 1991.

[14] J. Cahill, "Psychosocial aspects of interventions in occupational safety and health," American Journal of Industrial Medicine, vol. 29, no. 4, pp. 308-313, 1996.

[15] C. L. Cooper, P. J. Dewe, and M. P. O’Driscoll, Organizational Intreventions. Organizational Stress. A Review and Critique of Theory, Research, and Applications, Sage, Thousand Oaks, Calif, USA, 2001.

[16] A. Marine, J. Ruotsalainen, C. Serra, and J. H. Verbeek, "Preventing occupational stress in healthcare workers," Cochrane Database of Systematic Reviews, no. 4, p. CD002892, 2006.

[17] J. de Jonge and M. F. Dollard, Stress in the Workplace: Australian Master OHS and Environment Guide, CCH, Sydney, Australia, 2002.

[18] M. Whitehead, "A typology of actions to tackle social inequalities in health," Journal of Epidemiology and Community Health, vol. 61, no. 6, pp. 473-478, 2007.

[19] R. E. Ryan, C. A. Kaufman, and S. J. Hill, "Building blocks for meta-synthesis: data integration tables for summarising, mapping, and synthesising evidence on interventions for communicating with health consumers," BMC Medical Research Methodology, vol. 9, no. 1, article 16, 2009.

[20] S. Thorne, L. Jensen, M. H. Kearney, G. Noblit, and M. Sandelowski, "Qualitative metasynthesis: reflections on methodological orientation and ideological agenda," Qualitative Health Research, vol. 14, no. 10, pp. 1342-1365, 2004.

[21] D. Walsh and S. Downe, "Meta-synthesis method for qualitative research: a literature review," Journal of Advanced Nursing, vol. 50, no. 2, pp. 204-211, 2005.

[22] K. M. Parks and L. A. Steelman, "Organizational wellness programs: a meta-analysis," Journal of Occupational Health Psychology, vol. 13, no. 1, pp. 58-68, 2008.
[23] K. M. Richardson and H. R. Rothstein, "Effects of occupational stress management intervention programs: a metaanalysis," Journal of Occupational Health Psychology, vol. 13, no. 1, pp. 69-93, 2008.

[24] F. W. Bond, P. E. Flaxman, and S. Loivette, A business Case for the Management Standards for Stress. Research Report 431, Health \& Safety Executive, London, UK, 2006.

[25] J. J. van der Klink, R. W. Blonk, A. H. Schene, and F. J. H. van Dijk, "The benefits of interventions for work-related stress," American Journal of Public Health, vol. 91, no. 2, pp. 270-276, 2001.

[26] T. Saunders, J. E. Driskell, J. H. Johnston, and E. Salas, "The effect of stress inoculation training on anxiety and performance," Journal of Occupational Health Psychology, vol. 1, no. 2, pp. 170-186, 1996.

[27] V. Peñalba, H. McGuire, and J. R. Leite, "Psychosocial interventions for prevention of psychological disorders in law enforcement officers," Cochrane Database of Systematic Reviews, no. 3, p. CD005601, 2008.

[28] A. Martin, K. Sanderson, and F. Cocker, "Meta-analysis of the effects of health promotion intervention in the workplace on depression and anxiety symptoms," Scandinavian Journal of Work, Environment and Health, vol. 35, no. 1, pp. 7-18, 2009.

[29] V. S. Conn, A. R. Hafdahl, P. S. Cooper, L. M. Brown, and S. L. Lusk, "Meta-analysis of workplace physical activity interventions," American Journal of Preventive Medicine, vol. 37, no. 4, pp. 330-339, 2009.

[30] B. E. van Wyk and V. Pillay-Van Wyk, "Preventive staffsupport interventions for health workers," Cochrane Database of Systematic Reviews, vol. 3, p. CD003541, 2010.

[31] E. Noordik, J. J. van der Klink, E. F. Klingen, K. Nieuwenhuijsen, and F. J. van Dijk, "Exposure-in-vivo containing interventions to improve work functioning of workers with anxiety disorder: a systematic review," BMC Public Health, vol. 10, article 598, 2010.

[32] M. Egan, C. Bambra, S. Thomas, M. Petticrew, M. Whitehead, and H. Thomson, "The psychosocial and health effects of workplace reorganisation. 1. A systematic review of organisational-level interventions that aim to increase employee control," Journal of Epidemiology and Community Health, vol. 61, no. 11, pp. 945-954, 2007.

[33] A. D. LaMontagne, T. Keegel, A. M. Louie, A. Ostry, and P. A. Landsbergis, "A systematic review of the job-stress intervention evaluation literature, 1990-2005," International Journal of Occupational and Environmental Health, vol. 13, no. 3, pp. 268-280, 2007.

[34] BOHRF, Workplace Interventions for People With Common Mental Health Problems, British Occupational Health Research Foundation, London, UK, 2005.

[35] D. Edwards and P. Burnard, "A systematic review of stress and stress management interventions for mental health nurses," Journal of Advanced Nursing, vol. 42, no. 2, pp. 169-200, 2003.

[36] L. R. Murphy, "Stress management in work settings: a critical review of the health effects," American Journal of Health Promotion, vol. 11, no. 2, pp. 112-135, 1996.

[37] S. I. Giga, A. J. Noblet, B. Faragher, and C. L. Cooper, "The UK perspective: a review of research on organisational stress management interventions," Australian Psychologist, vol. 38, no. 2, pp. 158-164, 2003.

[38] H. P. van der Hek, "Occupational stress management programmes: a practical overview of published effect studies," Occupational Medicine, vol. 47, no. 3, pp. 133-141, 1997. 
[39] C. Mimura and P. Griffiths, "The effectiveness of current approaches to workplace stress management in the nursing profession: an evidence based literature review," Occupational and Environmental Medicine, vol. 60, no. 1, pp. 10-15, 2003.

[40] K. R. Parkes and T. J. Sparkes, Organizational Interventions to Reduce Work Stress: Do They Work? Research Report 193, Health \& Safety Executive, Norwich, UK, 1998.

[41] S. Michie and S. Williams, "Reducing work related psychological ill health and sickness absence: a systematic literature review," Occupational and Environmental Medicine, vol. 60, no. 1, pp. 3-9, 2003.

[42] N. Caulfield, D. Chang, M. F. Dollard, and C. Elshaug, "A review of occupational stress intrventions in Australia," International Journal of Stress Management, vol. 11, no. 2, pp. 149166, 2004.

[43] C. Cancelliere, J. D. Cassidy, C. Ammendolia, and P. Cote, "Are workplace health promotion programs effective at improving presenteeism in workers? a systematic review and best evidence synthesis of the literature," BMC Public Health, vol. 11, no. 1, pp. 395-434, 2011. 


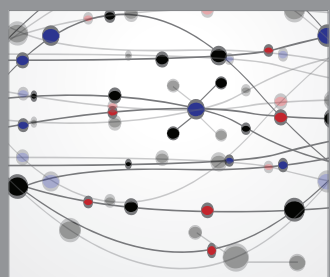

The Scientific World Journal
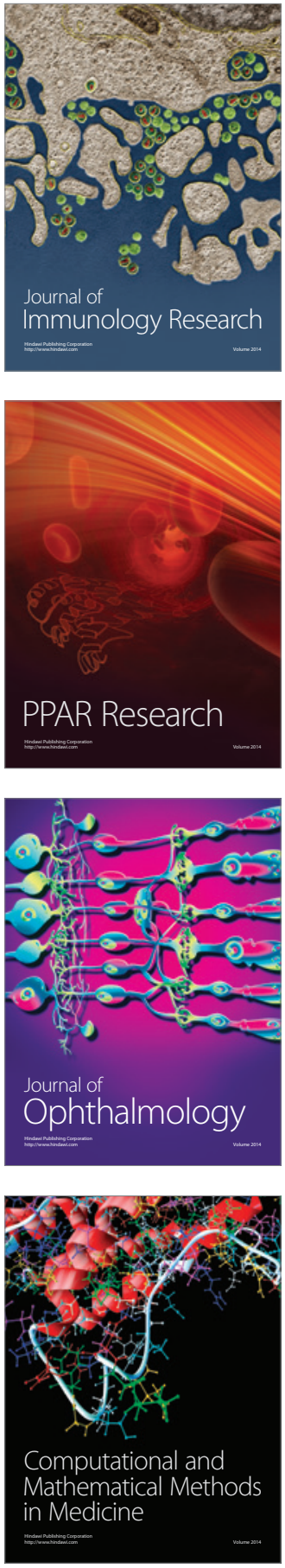

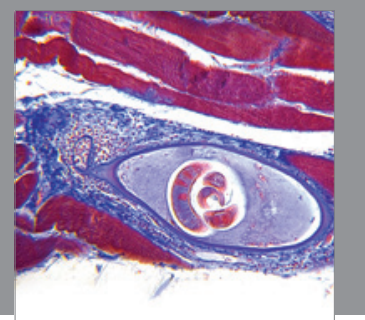

Gastroenterology

Research and Practice
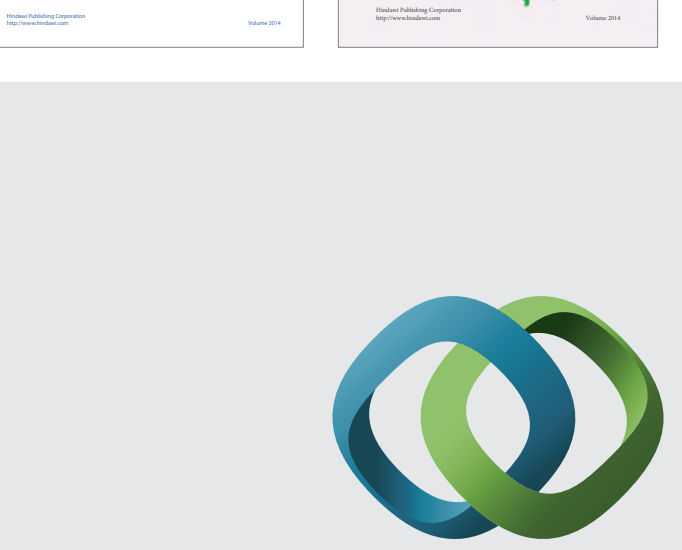

\section{Hindawi}

Submit your manuscripts at

http://www.hindawi.com
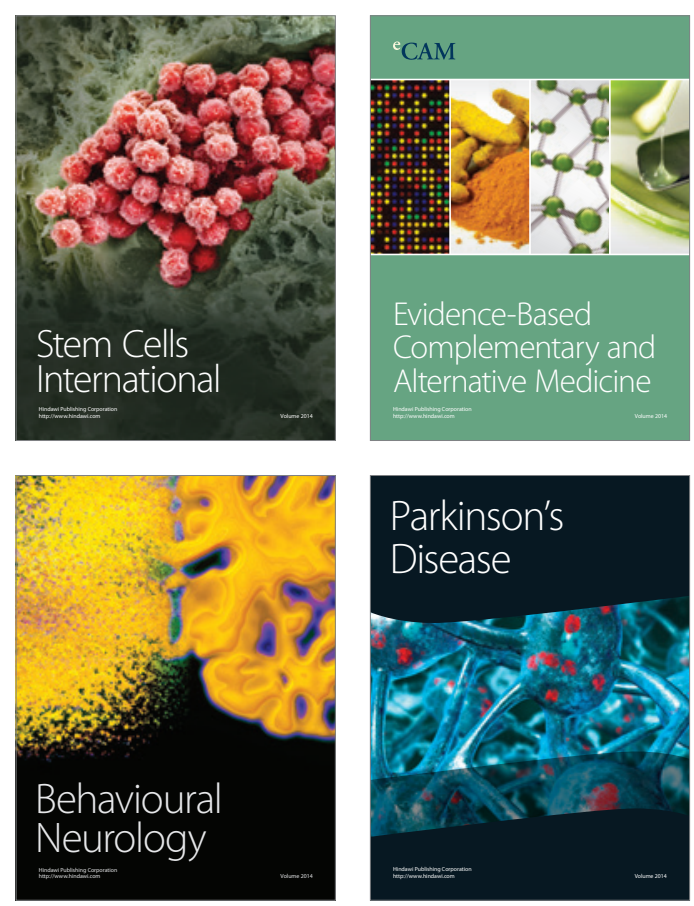

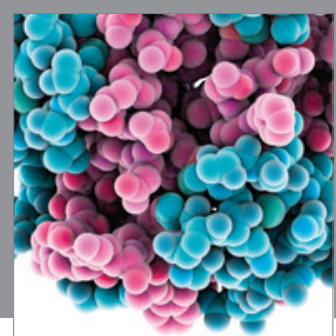

Journal of
Diabetes Research

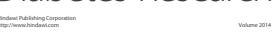

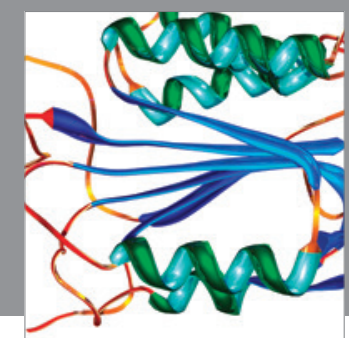

Disease Markers
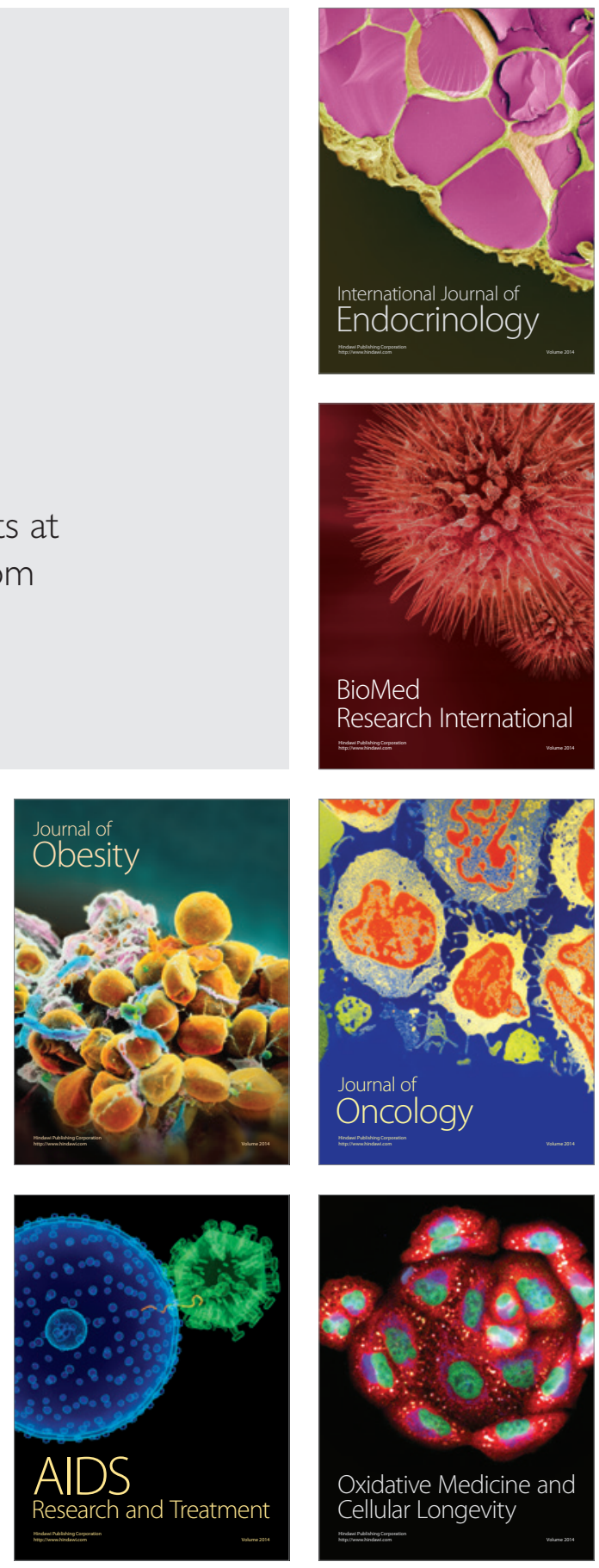